\title{
Editorial
}

\section{LA REHABILITACIÓN INTEGRAL DENTRO DE LA LEY DE TALENTO HUMANO}

E sperada por mucho tiempo, finalmente fue sancionada y promulgada por el propio Presidente de la República la Ley de Talento Humano que cobija, sin excepción a todos los profesionales de la salud. Esta Ley denota un profundo análisis, enmienda fallas anteriores, introduce instrumentos para despejar dudas y ofrece nuevas herramientas para avanzar positivamente hacia la calidad en la atención.

La denominación de talento humano se extiende según la ley "a todo el personal que interviene en la promoción, educación, información de la salud, prevención, diagnóstico, tratamiento, rehabilitación y paleación de la enfermedad de todos los habitantes del territorio nacional"; es decir, que nadie comprometido con la prestación de los servicios está por fuera de los alcances mandatarios del acto legislativo. El objeto de la importante Ley es asegurar la calidad mediante el ejercicio idóneo de cada profesión u ocupación en salud, desde luego tomando como termómetro la satisfacción de los usuarios de los servicios.

Claro está, que así se fijen directamente responsabilidades, obligaciones y derechos, muchos aspectos consignados en el texto seguramente serán reglamentados para lograr una cabal interpretación y por tanto, el cumplimiento efectivo de lo estipulado.

La Ley ordena que "todo el personal de salud que actualmente ejerza una profesión u ocupación cuenta con un periodo de tres años para certificarse mediante inscripción en el Registro Único Nacional". Así mismo establece que habrá "un proceso de recertificación obligatoria como mecanismo para garantizar el cumplimiento de los criterios de calidad en la prestación de los servicios". Esta recertificación la llevarán a cabo los Colegios Profesionales, por delegación de funciones del Ministerio de Protección Social, el cual supervisará el estricto desarrollo del proceso. La normatividad para la recertificación actualmente está en fase de reglamentación, para iniciar su cumplimiento una vez transcurridos los seis meses que prevé la ley. Lo cierto es que los profesionales sin excepción deberán recertificarse cada 5 años como mínimo para poder laborar vinculados a alguna institución o para ejercer en forma independiente.

De igual manera los programas de formación en áreas de la salud, según lo expresó directamente el primer mandatario de la nación en el acto de promulgación de la ley, se someterán a la acreditación de calidad de manera obligatoria; esto significa que operará un real concertación entre los Ministerios de Protección Social y Educación, para los efectos de expedir los decretos reglamentarios correspondientes y los organismos de control entrarán a operar activamente para supervisar el efectivo cumplimiento de este laudable propósito. Bien importante es esta parte de la Ley, en cuanto que busca enmendar lo relacionado con la perniciosa proliferación de centros educativos, no sin razón calificados por muchos como "universidades de garaje", que en el mejor de los casos ofrecen atractiva fachada, pero analizados en su esencia carecen de recursos de todo orden para garantizar al país, un producto profesional competente desde todo punto de vista, acorde con los requerimientos de nuestra realidad nacional. 
Un aspecto muy positivo de la Ley es la reafirmación de la autonomía profesional, un tanto debilitada en los últimos años, a merced de perversas interpretaciones que dieron a la seguridad social en salud, organizaciones más interesadas en el lucro que en la satisfacción de los usuarios. Muchas veces sometieron a los profesionales a amañadas normas de tiempo para atención de pacientes y a la prescripción de medicamentos y exámenes de bajo costo e indiscriminada calidad. Por fortuna, el nuevo acto legislativo deja en claro que "el personal de salud debe ejercer su capacidad para deliberar, decidir y actuar", lo cual significa que el profesional retoma algo que debe ser la esencia de su ejercicio y con lo cual vuelve a ser confiable ante su paciente.

Actualmente está en estudio, dentro de las prerrogativas de reglamentación que establece la ley, lo correspondiente a las tarifas para la prestación de los servicios, lo relacionado con protección laboral, lo mismo que el plan de estímulos e incentivos para los integrantes del talento humano en salud. Se presume que deben definirse todos los aspectos de vinculación laboral, así como el piso tarifario dentro de rangos más justos y razonables.

En el área de investigación, bastante relegada tradicionalmente en el país, la definición de "establecer programas de estímulos a la investigación”, consignada en el texto legislativo, permite esperar un impulso importante que ya se avizora desde años atrás a merced de esfuerzos de organismos oficiales con Colciencias a la cabeza. Un mayor estímulo, en tan importante área, pone en evidencia que somos conscientes que con investigación hay mayor desarrollo científico y con la unión de esos dos factores es visible el crecimiento tecnológico, y con la conjunción de todos los anteriores será evidente el crecimiento económico del país.

Es de todos conocido el austero apoyo presupuestal que se brinda a este campo; apenas si pasamos del 0,5\% del PIB destinado a investigación científica a casi el 1\%, aún así continuamos en los últimos puestos entre los países subdesarrollados, pero al menos es un avance y con los esfuerzos comprometidos nos acercamos a una perspectiva favorable, que de cristalizarse, redundará en impulso al desarrollo tecnológico y obviamente al mayor crecimiento económico.

Como parte fundamental de ese gran ejército profesional comprometido con la salud de los colombianos, en área de tanta importancia como lo es la de la rehabilitación, nuestra Institución Universitaria, continúa con el compromiso inmodificable de mejoramiento permanente de la calidad, no sólo en sus programas académicos, ajustados actualmente a las modernas metodologías, sino en temas como el de la proyección social, el bienestar de estudiantes, docentes y egresados, y el impulso a la investigación como una característica que debe distinguirnos.

Gustavo Malagón-Londoño, Rector 